\title{
11 A Late Iron Age Palisade Facing the Karmsund Strait
}

A stone construction, 2.2-3.7 metres wide, about 30 metres long, 0.3-0.6 metres high, and probably built in the 7th century, was discovered on the edge of the Avaldsnes settlement plateau. It probably represents the remains of the foundations for a wooden palisade. Its original extent is unknown, and some stones were likely removed over the centuries for reuse in fences and buildings. The construction's parallel rows of stones and the scatter of stones between them, as well its position atop a steep slope on the edge of the plateau, are comparable with the low stone walls or ramparts of 3rd-6th-century fortifications elsewhere on the Scandinavian Peninsula. Around 400 such fortifications are known in Norway, in Sweden more than 1000. While there are possible exceptions such as Halsstein in Trøndelag, only rarely do Norwegian fortifications appear to have been permanently settled. The Avaldsnes fortification represents another possible exception, indicating that the phenomenon of hilltop settlement and enclosed farms is not restricted to continental Europe and Sweden. Material for comparison is provided by approximately 40 Iron Age settled fortifications that have been found in Sweden, especially in the Mälar region, most of which were abandoned by the mid-6th century, and therefore pre-date the Avaldsnes palisade. Nonetheless, a few sites in the Östergötland show continued use into the late Iron Age and the construction of the 8th-century Birka fortifications, though approximately a century younger than A20, provides a late Iron Age parallel.

As part of a palisade that contributed to defence of the settlement, the stone construction served a functional purpose; it also would have contributed to Avaldsnes' monumental façade towards the Karmsund Strait, and may have met other demands such as enclosure, demarcation, and the like. The main problem in identifying the precise nature of the Avaldsnes construction is the uncertainty regarding its original extent. Its defensive capacity would be limited if it provided only an incomplete enclosure of the area, leaving other parts of the headland easily accessible to attackers.

This chapter describes the physical remains of the stone construction and considers the validity of the suggested interpretations as a palisade foundation with function similar to those at hilltop settlements otherwise found in Sweden and in Germanic areas close to the Roman Limes.

In the eastern- and southernmost parts of Area 6, above the steep slope facing the Karmsund Strait, the stone construction A20 was exposed (Fig. 11.1). Area 6 comprises a flat surface south of the monumental Kjellerhaug grave mound, about 1 metre higher than the terrain to the north and west. The area is delimited to the east and south by a geologically shaped scarp with a steep drop of about 3-5 metres, followed by uneven and rocky terrain sloping towards the sea. While its interpretation as a palisade foundation was suggested quite early during the Avaldsnes Royal Manor (ARM) excavation, other possible interpretations were considered and discarded. The lack of building remains ruled out interpretation as a house terrace similar to those found at, for example, Lejre in Sjælland (Christensen 2015:71-4) or Runsa, Gamla Uppsala, Helgö, and Fornsigtuna in the Mälar region (Ljungkvist 2006:50-75; 2013; Olaus- 
son 2009:47, 2011b). Protruding bedrock made it unsuited for use as a built-up road, such as the contemporary road at Norra Gärdet at Uppsala (Duczko 1993:35; 1996:41, 115-22). It appears most likely that A20 is the remains of a palisade foundation of unknown original height and length. The structure was subjected to a limited excavation focusing on exposing the borders and examining the stratigraphy and construction. The uppermost stones in A20 and soil in parts of the construction were removed; only two cross-cutting trenches in the northern and southern segments, respectively, were fully excavated through underlying deposits and down to the bedrock. These sections also provided suitable contexts for sampling. The construction was dated to Site Period IV (AD 600-900; below, and Østmo and Bauer, Ch. 6).

\subsection{The physical remains}

A20 consisted of two parallel rows of large stones 2.2-3.7 metres apart, with the gap between them filled by a scatter of stones of various sizes mixed with soil. The two rows followed the shape of the plateau edge, beginning at the south-eastern base of the Kjellerhaug grave mound and stretching south-south-west for almost 30 metres, interrupted only by a protruding formation of bedrock in the middle of the stretch. The size and shape of the stones in the construction varied within different parts, and it was unclear whether the preserved construction had been part of a larger structure.

In his description of archaeological monuments at Avaldsnes, Johan Koren Christie (1842:334) mentions a flat area south of the mid-19th-century rectory garden that likely corresponds to the plateau in Area 6. According to Christie, this flat area was sharply cut in a straight line towards east. It seems likely that the stone construction contributed to this sharply defined eastern edge, and that A20 at this time might have been better preserved - though likely not of greater height - than it was prior to excavations in 2012. In that case, quite a few stones would have been removed after Christie's visit, resulting in a reduced volume and a less defined eastern edge. According to local tradition at least going back to the first half of the 20th century, the area carried the name Borgjå, meaning 'The Fort' (Utvik 2008, and pers. comm. 2016). The age of this tradition is uncertain, but the plateau above the sloping terrain or even visible stones in the stone construction could have contributed to such an association. A foundation for a small shed was placed directly on top of A20, containing broken, modern window glass. The digging of the foundation trench would have exposed stones; thus, their presence will have been known.

Protruding bedrock divided the construction into a northern and a southern segment; these segments were slightly angled and did not form a straight line. The northern segment also decreased in width towards the north where it curved moderately westwards and onto the base of the Kjellerhaug grave mound. The eastern row 


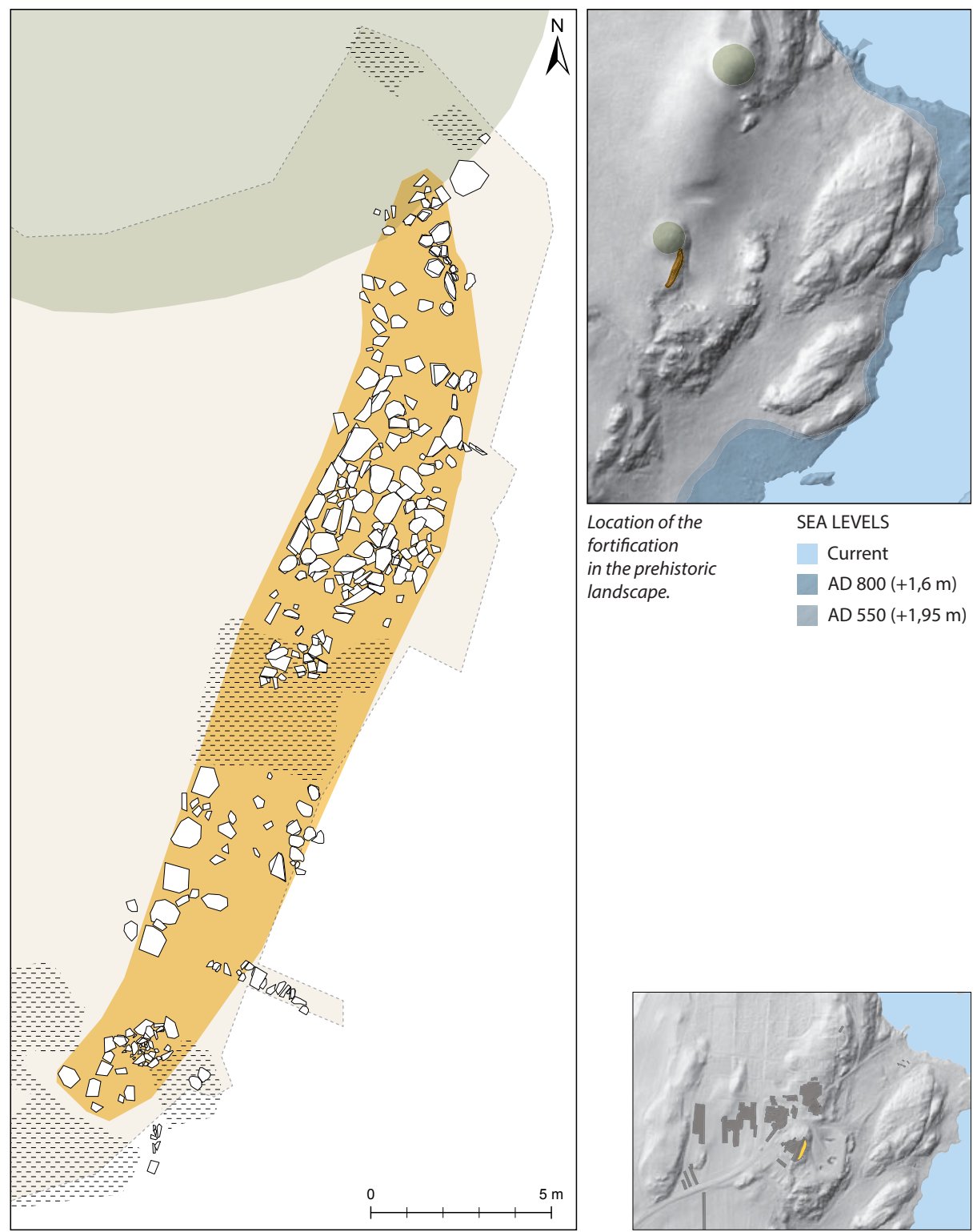

Fortification

$=-$ Bedrock

Excavated area

$\bigcirc$ Stone

Grave mound

Fig. 11.1: Overview of the stone construction A20 situated along the scarp edge. Illustration: I. T. Bøckman, MCH 
of stones was more irregular and less continuous than the western; probably because stones have slid down the slope. Thus, the width of the construction may have been reduced. Where the foot of the grave mound met the slope, a dip in the terrain was filled by two levels of stones.

The border stones were not uniform in terms of size, shape, or placement. Border stones in the construction were placed in one or two layers, probably depending on the shape and size of the stones. The slightly curved northernmost part consisted of two layers of rounded stones with cross-sections measuring maximally between 0.3 and 0.6 metres. In the straight part of the northern segment, the western border stones were fairly rectangular and relatively thin slabs, compared to the otherwise rounded stones or boulders within the construction (Figs. 11.1-2). The slabs measured 1 by 0.5 metres $\pm 20 \mathrm{~cm}$ and were only approximately $15-20 \mathrm{~cm}$ thick. They were neatly placed along the construction's border, partly overlapping to form two layers. In the southern part there was only one layer of stones in the western border row (Fig. 11.3). These stones were rather large boulders, mainly in the shape of rounded cubes with cross-sections measuring maximally 0.7-0.9 metres, with an internal spacing of approximately $0.3-0.6$ metres. The south-eastern border row was only partly uncovered during excavation and seemed to be constructed of rounded stones with cross-section measurements between and 0.35 and 0.45 metres, more similar to the border stones in the slightly curving eastern side of the northernmost segment than to the opposing western row.

The gap between the border rows was filled by stones of varying sizes and shapes ranging mainly within cross-sections of 0.2 to 0.6 metres mixed with humic soil. The placement of stones in the outer rows seem to have occurred before the addition of soil, but most of the stones between the rows, regardless of size, seemed to have been added simultaneously with the soil: the soil lay both between and underneath stones. In the photos and measurements, the southern part appears to include fewer and slightly smaller stones, but this is partly a skewed image as less soil was removed during excavation of this segment, leaving a number of stones completely or partly covered. In the northern segment, however, a greater number of stones were exposed during excavation and some of the uppermost stones and soil fill was removed in order to reveal construction details. This exposition showed that the area immediately north of the protruding bedrock contained fewer stones than the area further north, possible due to modern truncations in the former.

In the southernmost end of the construction, the stones were more thoroughly exposed during excavation with the aim of identifying an eventual end or continuation. Instead, the construction petered out, leaving unanswered the question of whether this was an original end or one created by subsequent truncation; the latter appears the more likely alternative.

Immediately south of A20, an approximately $30 \mathrm{~cm}$ deep natural step in the bedrock running east-west marks the south-eastern end of the plateau (Fig. 11.3). South and east of this, the terrain becomes increasingly uneven and slopes more 

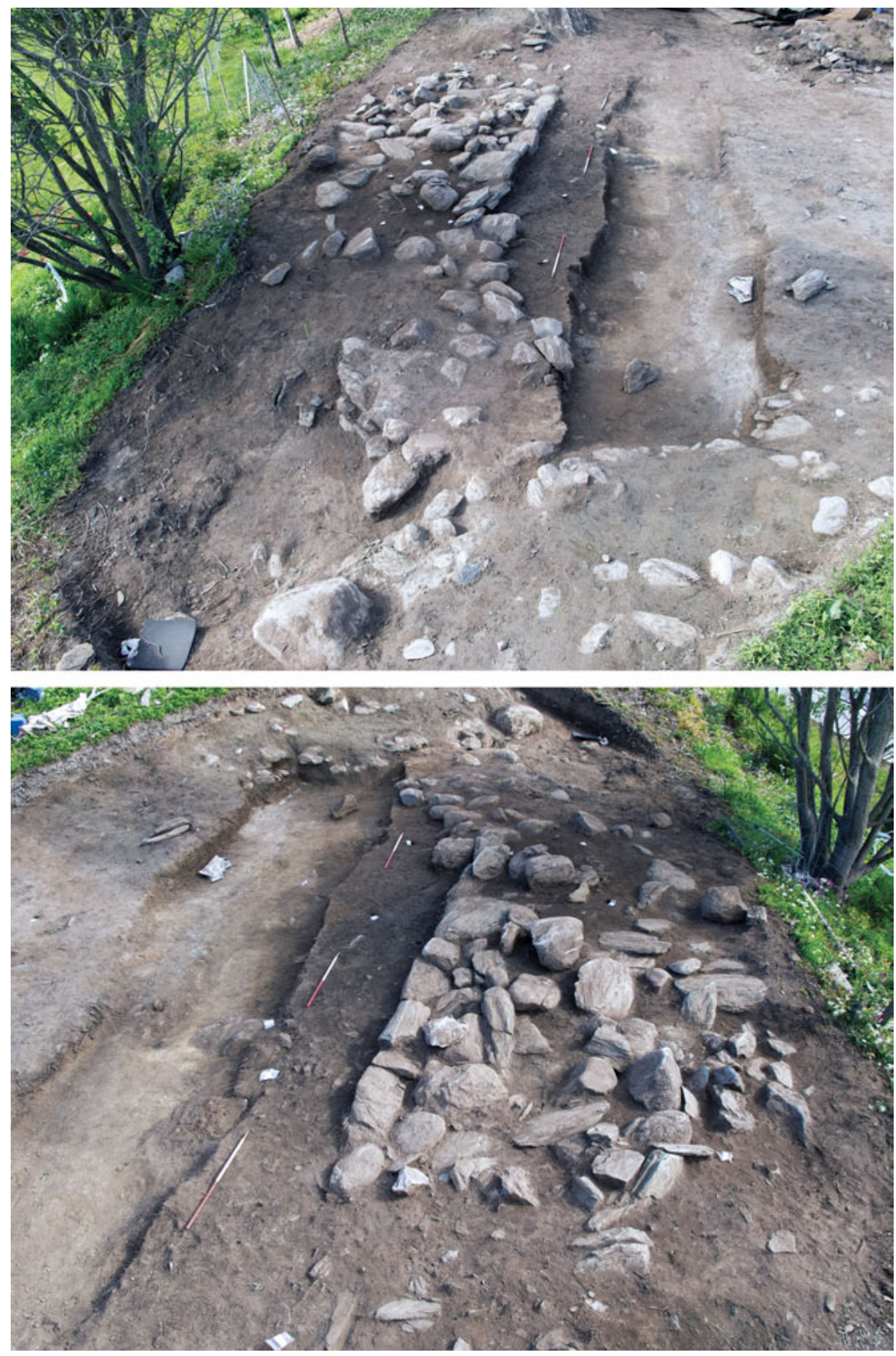

Fig. 11.2: The northern segment of the stone construction. The northernmost part curving up onto the Kjellerhaug, two layers of stones visible (above, facing south-southeast). The northern part of the main segment of A20 (below, facing north). Photo: $\mathrm{MCH}$. 

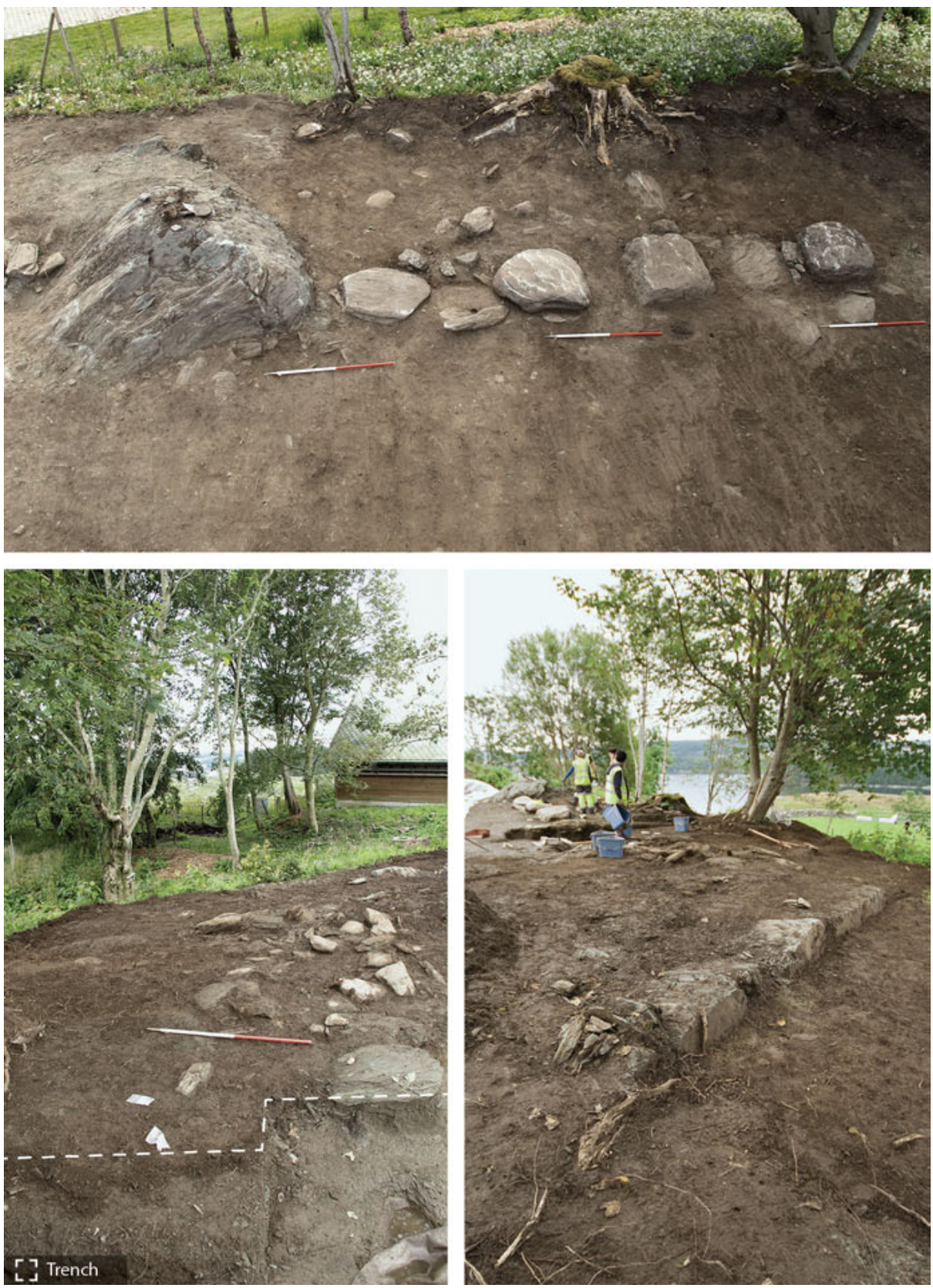

Fig. 11.3: The southern segment of stone construction A20: The northern part of that segment (above, facing east); the southernmost part slightly curving towards west (below left, facing south); the natural step in the bedrock where the terrain starts to slope towards the south and east (below right, facing north). Photo: $\mathrm{MCH}$. 
sharply towards the strait. The plateau continues towards the west and south-west, but modern buildings and truncations made excavations futile. Similarly, to the north, the stone construction could be traced as far as the foot of the partly reconstructed Kjellerhaug grave mound, where it was found to be slightly overlying the mound. It remains unknown whether this represents the actual end of the construction or if it originally had run across and beyond the grave mound. The stone construction theoretically could have circumscribed only the plateau immediately south of the Kjellerhaug. Alternatively, the stone construction could have continued to the north of the grave mound along a slightly elevated ridge, running all the way to the Flaghaug grave mound approximately 125 metres further north. Immediately north of the Kjellerhaug grave mound, modern elements such as a parking lot and pedestrian walkway have transformed the landscape. The excavation trenches on the parking lot showed an area greatly affected by recent activities; preserved deposits and features from prehistoric times were limited. The medieval stone-built cellar prevented any further search for a possible continuation in that direction (Bauer, Ch. 14).

\subsection{Dating}

Samples for micromorphology analyses were retrieved from the section walls of the two narrow trenches dug across the construction and into the underlying deposits. Analyses of these samples show that the A20 stones were placed mainly on layers made of general farmyard waste with inclusions of episodic latrine dumping and debris from ovens (layers 1 and 4 in Fig. 11.4), but also occasionally on features (hearth A37770, cooking pit 9 in Fig. 11.4) or partially on an underlying surface formed by colluvial processes (Fig. 11.4), possibly induced by cultivation or animal stocking further west (Østmo, Ch. 9; Macphail and Linderholm, Ch. 17:415). Based on stratigraphy, datable finds in the waste deposits, and the placement of some the A20 border stones within the layer, it seems likely that the waste deposits were subjected to some degree of levelling or reworking prior to or in relation to the construction of A20, causing some of the stones to be set deeper into the waste deposits. Redeposited pottery in the waste deposits (layers 1 and 4 and similar patches outside the trenches) included bucket-shaped pottery of early and late types, partly mixed, though there was a slight clustering, possibly from the same or similar pots with early pottery (AD 350-450/500) in and near layer 4 and late pottery (AD 450-550) in and near layer 1 (Kristoffersen and Hauken, Figs. 21.4 vs 21.14 and 21.20 respectively). One of the waste layers (layer 1 in Fig. 11.4) sealed off two small ovens or furnaces, which were dated AD 237-333 (Ua-45336) and AD 535-601 (Ua-45334) (Fig. 11.4). In addition, the dated charcoal from the overlying waste layers [layers 1 and 4 in Fig. 11.4, Ua-45332 (not sampled from section) and Ua-45339] provided a terminus post quem date for A20 to $\mathrm{AD}$ 414-532 and AD 236-333 respectively. As these radiocarbon dates are overlapping 

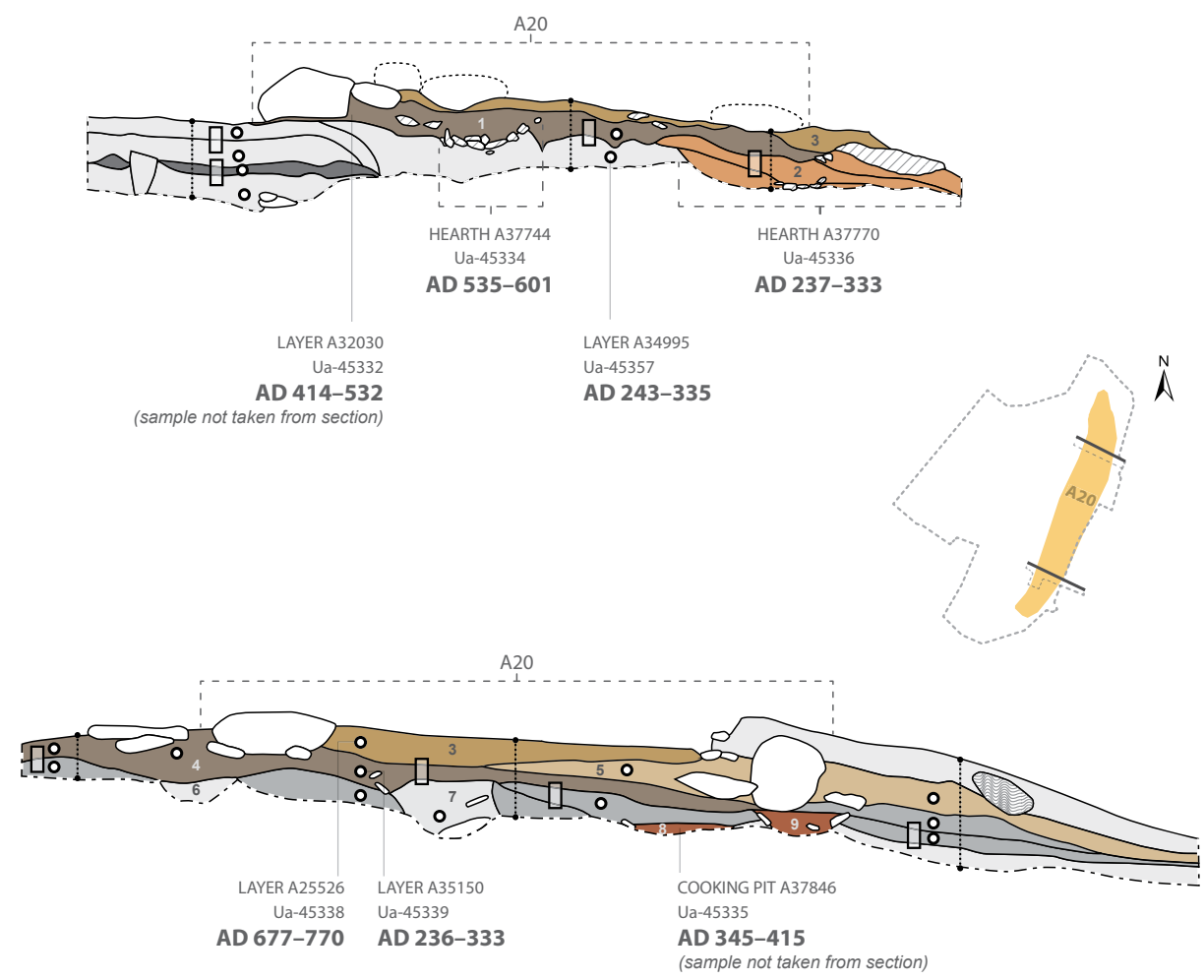

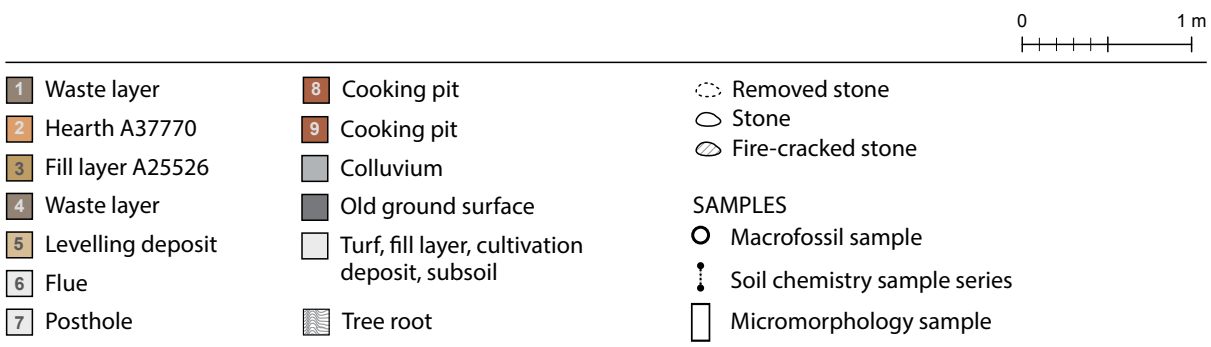

Fig. 11.4: Two trenches through A20 showing the underlying waste layers, ovens, and cooking pits as well as the placement of the border stones in A20. Some stones in the northern trench have been removed to permit the establishment of the section. Illustration: I. T. Bøckman, $\mathrm{MCH}$ 
or slightly earlier than the respective underlying hearths, they likely represent redeposited waste reflecting a general period of artisanal production occurring during SP III, ending around AD 600 (Østmo, Ch. 9). The many fragments of Roman Iron Age and Migration Period pottery found in the waste layer support this conclusion.

The A20 stone construction is difficult to date directly as it does not include contexts that can provide primary radiocarbon dates. It was covered only by the grassturf and lacked overlying dateable contexts or finds providing a terminus ante quem, except for the foundation for a modern gazebo or garden outbuilding mentioned above. Two charcoal samples from the infill between the stones in A20 were radiocarbon dated Cal AD 347-421 and Cal AD 677-770 (Ua-45331 and Ua-45338 respectively). It is uncertain what these bits of charcoal date, however, as the soil is redeposited from older contexts and thus contains finds and inclusions pre-dating the construction and use period of A20 (below). In better-preserved palisade foundations or ramparts, charcoal concentrations have been taken to represent wooden elements within the stone wall intended to stabilise the wall and possibly support a wooden superstructure (Olausson 1995:149). At many of the Swedish fortifications and hilltop settlements the palisade has been successively burnt, destroyed, and rebuilt several times (Olausson 2009:37). In A20, the preserved stratigraphy and amount of charcoal were too sparse to serve as reliable evidence of burnt construction elements.

The construction layer between the stones (layers 1 and 5 in Fig. 11.4) contained a part of an arrow with the blade either rusted away or broken off. The arrow (S12772/2) has a socket, but its type cannot be precisely identified due to the lack of a blade; however, it is likely either R213 or R535. Peter Lindbom (2006; 2009) argues that tang arrows are the indigenous type in Scandinavia whereas socket arrows stem from an elite foreign influence. He classifies R213 and R535 as arrows of a western Norwegian tradition in the period $\mathrm{AD} 300-500$ with precedents in the Roman auxiliary arrows probably brought to Scandinavia by returning warriors (Lindbom 2006:4). R535 resurfaces with the establishment of the Merovingian kingdom in the 6th century and is found in Vendel, Valsgärde, as well as the mountainous and valley areas of eastern Norway up to c. AD 600 (Gudesen 1977:108; Lindbom 2006:195-204). Because burials from the Merovingian Period in Rogaland contain few arrows altogether and none with sockets (Rønne 1999b, catalogue), a reasonable estimate for the age of the S12772/2 arrow in A20 is the period AD 300-500. As such it is seemingly one of several older inclusions in redeposited soil within A20, along with sherds of pottery likely of a Migration Period date (e. g. S12772/85; Kristoffersen and Hauken, Fig. 21.8).

In light of the recurring evidence of rebuilding at Swedish sites, it would be problematic to put too much weight on single fragments of charcoal inclusion in the infill between the stones as an indication of its period of use. Rather, the terminus post quem dates from underlying features and redeposited artefact inclusions in combination with horizontal stratigraphy are the best available indications as to when the construction was built. Contextualising the construction in terms of the various phases of 
production in Area 6 clearly suggests that in SP III the entire area south of the Kjellerhaug grave mound, as well as beneath the stone construction, was used for metalwork, possibly pottery production and other artisanal work (Østmo, Ch. 9:158-9). From AD 600, a new type of production was established, consisting of the processing and likely storage of grain and other foodstuffs. All features with high concentrations of grain and 14C dates belonging to SP IV lay clearly west of the stone construction, seemingly respecting a construction standing at that time. The A20 infill's lack of modern or medieval pottery, clay pipes, or well-preserved animal bone - the type of finds omnipresent in medieval and post-medieval deposits examined during the ARM excavation - supports a pre-medieval date. Taken together, the vertical stratigraphic relations and the terminus post quem dates based on finds and dated charcoal indicate that A20 was constructed no earlier than c. AD 600; the horizontal stratigraphic relations to food-related processing and the lack of medieval finds makes it likely, though not certain that the construction was erected already early in SP IV and that it remained functional or at least preserved as a substantial ruin throughout SP IV and early SP V. Only two features in Area 6 date to the 11th-13th centuries AD, impeding conclusions on the activities taking place here as well as a date for the downfall of A20. It remains uncertain whether A20 was reduced to its current state of preservation immediately after it fell out of use or whether the process occurred in several stages, permitting later phases of superimposed activities. In the latter case, any traces of such activities would have been eradicated by later removal and reuse of stones from the construction.

\subsection{Fortifications and hilltop settlements}

The approximately 1,400 fortified sites on the Scandinavian Peninsula share common traits such as stone foundations or ramparts of stone and earth that supported wooden palisades. These sites are found mainly at elevated spots partly protected by natural obstacles in the landscape; some of these appear to be focal points in a social-political landscape, occupying a strategic position permitting control of the vicinity. Most sites dating to the 4th-6th centuries are interpreted as defensive fortifications, whereas non-military enclosures normally pre-date the 4th century (Olausson 1995:156; Skre 1998:266-7; Ystgaard 2003:22, 25-7). On the Swedish mainland, most sites in the Mälar region were abandoned by AD 550, while in Östergötland a few sites continued to be used into the late 7th century (Olausson 2009:38). Nevertheless, as small number of fortified sites were established in the late Iron Age, such as at Birka and Stora Karlsö (Zachrisson 2009).

The fortifications in Norway and Sweden from the period AD 300-550 generally consist of irregular semi-circular ramparts, benefitting from natural obstacles such as cliffs or steep slopes (Näsman 1996:147; Olausson 2010:26; Hedenstierna-Jonson et al. 
2013:286-7). Several researchers have argued against identifying these fortifications by the traditional term bygdeborg, generally translated as hill fort, which carries the association of providing refuge for the district - Norwegian bygd (Skre 1998:266; Ystgaard 2003; 2014:164). Following these researchers, I will use instead the more neutral term fortification. Late Roman and Migration Period fortifications without traces of settlement could have functioned as temporary refuges for groups of warriors in times of trouble, used actively as a base for either defence or attack, as satellite fortification within a hierarchy. The lack of building remains and space for storage of provisions, livestock, and the like suggests that such fortifications were unlikely to have served as refuge for a district population (Hedenstierna-Jonson et al. 2013:287).

In order to distinguish between fortifications with and without settlement and to underline the former's similarities with the höhensiedlungen in Germanic areas immediately north of the Roman Limes, I will employ the term "hilltop settlement" (Olausson 2009, 2010; Hedenstierna-Jonson et al. 2013:287-8). Hilltop settlements are generally complex, reflecting an imported, elite, Roman-influenced lifestyle that combined fortification with elite dwellings, craft production - especially non-ferrous metalwork and other prestigious objects - the milling of grain and the baking of bread. The evidence shows that hilltop settlements were characterised by elite artefacts as well as a prestigious diet, which included meat and bread, according to osteological analyses and finds of rotary querns (Olausson 2009:52; Zachrisson 2009:43-5; Ystgaard 2014:150).

The most relevant comparisons for the Avaldsnes stone construction are to be drawn from the approximately 40 Swedish hilltop settlements from c. AD 300-550. Although most of these were abandoned by the time the Avaldsnes construction was built, the few Swedish sites that are contemporary with A20 appear to be rooted in the Migration Period fortification tradition, and are therefore the most suited amongst available parallels. In Ireland, enclosed settlements, or cashels, are also known; although their layout and construction differ, they provide a contemporary parallel elsewhere in north-western Europe. Regarding the approximately 40 Swedish hilltop settlements, Olausson (2009; 2010) draws parallels to the Alemannic hilltop settlements along the Roman Limes. These settlements, inhabited by Germanic leaders and their vassals, were characterised by fortifications, military equipment, non-ferrous metalwork, and Roman imports, and were generally abandoned by AD 500 (Steuer 1994; Bücker and Hoeper 2000:219-23). Based on finds of reticella glass and other imports, some of these hilltop settlements were resettled by elites in the 7 th century (Bücker and Hoeper 2000:228). Across Europe, a trend has been observed: a clear decrease in hilltop and fortified settlements in the centuries following the decline of the Roman Empire and a subsequent re-emergence in the 8th-10th centuries of a variety of fortifications (Boschetti 2016:129-31; Christie 2016:52-3; Tys et al. 2016:175-6, 183). As exceptions to this general trend, some Roman defences persisted in western Europe after the decline of the Roman empire, though no longer part of a military system (Tys et al. 2016:176). ln addition, fortified enclosures were emerging 
in northern Britain and Ireland as early as the 5th and 6th centuries, respectively. Whereas fortified settlements in Ireland increase in number towards the 7th century, Pictish northern Britain experienced the reverse trend, somewhat obscuring the overall pattern (Comber 2016; Noble 2016). The Irish ringforts vary in shape and material, with earthen or stone-built enclosing walls. While the ringforts of the 9th and 10 th centuries were increasingly defensive, the walls of settlements from the 6th and 7th centuries had "modest defensive capabilities, though possibly more for display purposes than practical application” (Comber 2016:12). As such, the early ringforts, contemporary with the Avaldsnes construction, were defendable rather than actively defended - in a pinch, they would protect people and livestock from wild animals and raids, but would be less effective against attack by a larger force of warriors. Thus, the abandonment of most Scandinavian fortifications and hilltop settlements c. AD 550 conforms with the general trend across Europe. Precursors to the general European renewed investment in fortification from the 8th century are seen in some areas, such as the above-mentioned insular examples. A similar deviation is seen in renewed or continued activity at singular fortifications on the Scandinavian Peninsula, at least into the 7th century (Ystgaard 2013, 2014:212-13; Olausson 2009:59-60). A small number of defensive structures were also built in Scandinavia during the Viking Age, but these are massive ringforts, linear embankments, or underwater pile barriers (Hedenstierna-Jonson 2006:49; Olausson 2009; Pedersen 2016). In Denmark, such linear defences were initiated already in the Roman Iron Age (Jørgensen 2003). According to Ulf Näsman (1996:148), most strategic defence systems in Denmark in the Early Iron Age were, as with most of the approximately 1,400 on the Scandinavian Peninsula, designed as defence against attacking forces, and were not permanently manned.

The approximately 40 Swedish hilltop settlements from c. AD 300-550 are often situated along communication routes (Näsman 1996:148; Olausson 1996:157). Similarly, Avaldsnes occupies an elevated plateau overlooking the strait, which was the key to control over seaways communication along the coast. Compared to heavily defended hilltop settlements such as Runsa (Fig. 11.5), the defensive elements at Avaldsnes are somewhat different; the stone construction is less voluminous and is only known from a small segment. Other sites, such as the enclosed magnate farm at Lindö Utmark, apparently have more in common with Avaldsnes; there the enclosure permitted defence of the farm and the enclosing wall may have had additional functions such as demarcation of various jurisdictional and societal borders.

In SP IV Avaldsnes lacks building remains from dwellings, though several indirect indications of settlement were observed. These include dumping of latrine waste, lack of observed pauses in the agricultural production, and continued activity in the southern end of the farmyard. Settlement indications are thus much stronger than on the numerous AD 300-550 fortifications elsewhere in Norway. As the full extent and character of the Avaldsnes SP IV settlement remain unknown, we cannot address in detail the similarities or differences compared to the large dwellings and halls found 


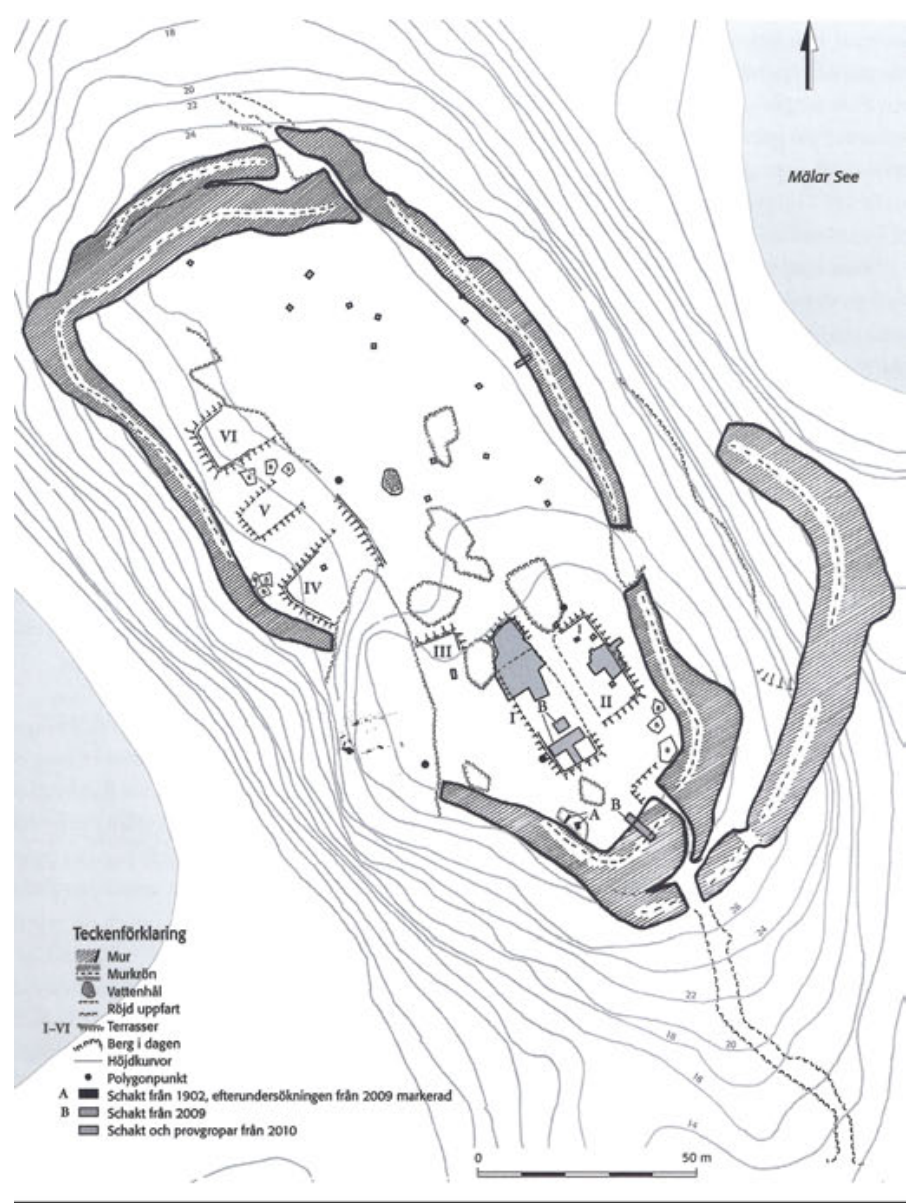

1

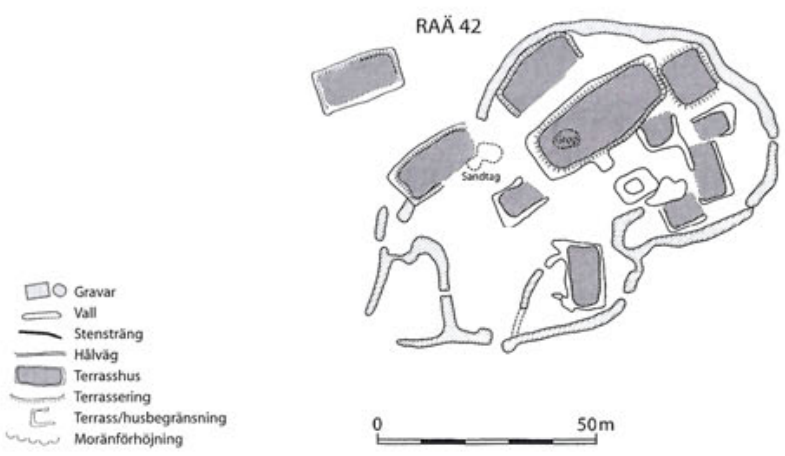

Fig. 11.5: Examples of defended and defendable Swedish parallels: Hilltop site, Runsa borg (upper, Olausson 2011a:fig. 1); Enclosed magnate farm, Lindö Utmark, Kärrbo parish (lower, Olausson 2009:fig. 1). 
at Runsa or similar large hilltop settlements. Nonetheless, its proximity to an area with contemporaneous processing and storage of agricultural produce as well as indication of copper alloy work permits a discussion of similarities of other aspects of hilltop sites.

\subsection{Construction and functionality of the Avaldsnes palisade}

At Swedish fortifications and hilltop settlements, repeated sequences of destruction by fire and resurrection are not uncommon, indicating that the palisades were rebuilt after destruction (Olausson 1995:149; 2009:37). By destroying fortifications and halls in an ostentatious display of victory, a successful attacker could garner prestige (Holmquist 2010). Although initially built in the mid-8th century, the fort rampart of Birka followed the traditional construction of Migration Period fortifications (suggested reconstruction in Fig. 11.6; Olausson 1997:402; Hedenstierna-Jonson 2006:49; Lundström et al. 2009:112; Hedenstierna-Jonson et al. 2013:294). The Birka battlement seems to have rested on frames of horizontal beams on top of the stone base, while other sites show the use of beams within the rampart combined with a palisade or a superstructure (for a presentation of various types of timber and stone fortifications, see Engström 1984:41-3).

It is difficult to assess the possible construction techniques of the palisade in A20 - probably, only the very bottom has been preserved. Nonetheless, there are indications of at least two layers of stones on the northern segment; the border rows there are evenly placed, creating an even, vertical front. The construction as a whole is less clear in the southern part, where there is a high degree of internal variation. The row of massive stones placed slightly apart constitute the western border of the construction, whereas the eastern border is marked with smaller stones more closely packed. These differences in shape, size, and placement of stones demonstrate that uniformity may not have been a requirement for the construction to function as intended; alternatively, it was constructed in separate segments or phases, or in a rush, making use of all available stones.

To function properly as a fortification, a palisade would need to close off a defended area. Much of the Avaldsnes headland remains unexcavated, making it impossible to assess whether A20 was one component in a broader defensive construction or merely an entirely local palisade enclosing a vulnerable or significant part of the settlement. Michael Olausson and Guy Halsall distinguish between defended and defendable sites, of which the latter are sites where a rampart's military aspect seems to be of secondary importance while the primary function is to seal off, proclaim superiority, or add to a monumental character (Halsall 2003:215; Olausson 2009:48). Olausson (2009:49) exemplifies this with the town wall of Birka and 

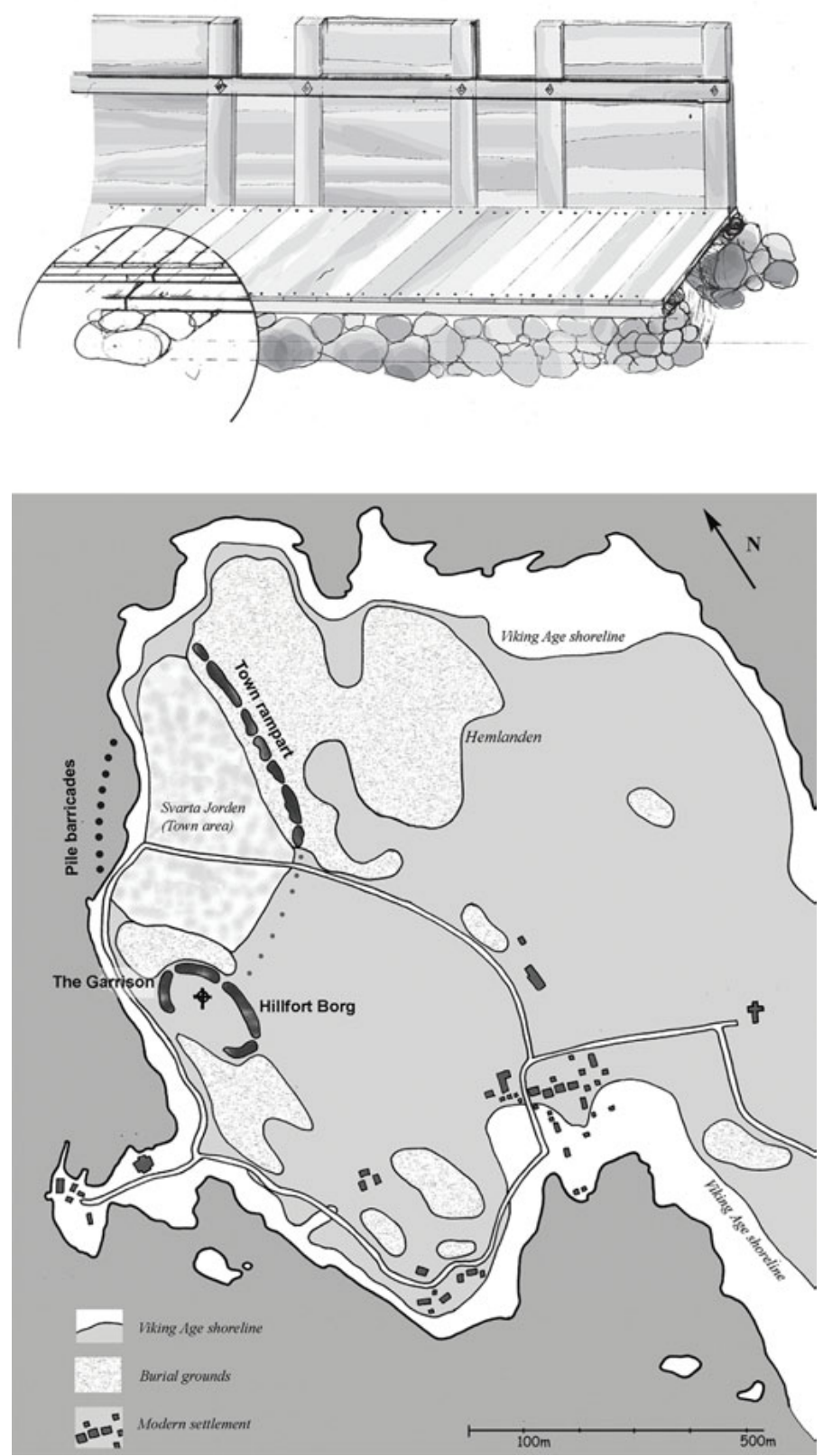

Fig. 11.6: Suggested reconstruction of the fort rampart with battlement at Birka (upper, Lundström et al. 2009:fig. 53). Overview of the military installations at Birka (lower, Hedenstierna-Jonson 2006:fig. 4). 
the enclosed magnate farm at Lindö Utmark in Västmanland, Sweden, arguing that they were "fortifiable only to a certain extent" by comparison with the heavily fortified sites such as Runsa Borg (Fig. 11.5; Olausson 2009:49). The defendable sites have insufficient ramparts or a placement not truly elevated from the surroundings, but the ramparts would still provide a limited degree of protection. Based on the excavated remains, A20 seems to have obstructed access to a part of the settlement from the east while adding to a monumental façade towards the strait; as such the Avaldsnes fortifications may be understood as defendable rather than defended.

Though walls such as the town rampart at Birka, bore a military appearance, they also would have been understood as providing societal and jurisdictional demarcation, displays of social status and the power of the ruler or leader in addition to defence (Halsall 2003:215-16; Olausson 1993:83; Olausson 2009:48). If not capable of withstanding the attack of an invading army, they could nevertheless offer defence against more minor attacks or play a strategic role in stalling an attack, providing refuge while buying time for negotiation (Halsall 2003:22; Olausson 2009:40, 59). Defensive aspects of such fortifications have generally received more attention than their offensive capabilities. Regarding Birka, Hedenstierna-Jonson (2006:66) points out that researchers have focused on the difficulties posed to defenders by the length and many openings in the town rampart, rather than its possible function as a "tactical base[s] for offensive warfare”. The presence of ramparts from the very start at Birka suggests that a military presence was a prerequisite for the security of the activities happening there.

In Olausson's (2009:44-5) general interpretation, the underlying causes for founding hilltop settlements were never solely military; moreover, their military aspect over time became secondary to the elite settlement's prerogative of co-locating crafts, trade, and political, economic, military, and symbolic power. In support of this thesis, Olausson (2009:38) cites the short, intensive period of fortification-building followed by periods no less affected by warfare but without fortifications. The military strategy of fortifications at hilltop settlements, argues Olausson (2009:36-7, 58-9), would have allowed the defenders to wait for the optimal time for battle outside the walls, hopefully deterring attack in the first place. The attackers' strategy would be to draw the defenders out by plundering the vicinity. The changes in defensive constructions reflected a general shift from a hierarchy of fortifications and hilltop settlements to combinations of linear defences at a larger scale to control waterways, secure harbours, and control the movement through bottlenecks in the landscape (Hedenstierna-Jonson et al. 2013:289, 299). Such changes paralleled changes in power structures, military strategy, and weaponry to suit new ways of battle (Ystgaard 2014:140-4).

In terms of its strategic location with control over the strait and the construction of a stone-built base assumed to have carried a wooden superstructure, Avaldsnes shares some characteristics with the Swedish hilltop settlements. In its other aspects, Avaldsnes appears to have been less fortified than the larger hilltop settlements in the Mälar district, closer in character to defendable, enclosed magnate farms such 
as Lindö Utmark. Shifting historical contexts may also have contributed to these differences. As suggested for the late Iron Age defensive structures at Birka, a military presence may have been important, but a palisade or rampart may have been used in offensive warfare as much as in defence; other aspects of the enclosure may have been equally important. Although it is uncertain whether the palisade terminated at the base of the Kjellerhaug grave mound or continued across the mound, the mound would have contributed to the physical stature of the palisade. The inclusion of graves is notable also in the town wall at Birka. There, some are believed to be younger graves dug into the wall while others are older graves included in or overlaid by the wall (Olausson 1993:69-77). Though undoubtedly a practical arrangement, such a foundation in an older monument could also have been intended to demonstrate a connection to the past or invoke a relation to existing power structures. This manner of relating to the past has been suggested by Lund and Arwill (2016:417-18, 422), exemplified by the late Iron Age ship settings at Glavendrup, where the stem and stern stones are set into Bronze Age grave mounds (Østmo and Bauer, Ch. 12).

Common traits of the hilltop settlements in Sweden include the presence of craft remains. The plateau west of A20, Area 6, bore traces of ovens, some of which were dated to SP III, some to SP IV and SP V, as well as clusters of small postholes dating mostly to SP IV and early SP V. However, in contrast to the Swedish hilltop settlements with abundant traces of non-ferrous metalwork, geochemical analysis at Avaldsnes were indicative only of low-scale copper alloy production (Cannell et al., Ch. 18; Østmo, Ch. 9:176-7; Olausson 2009:50-2; 2010:7-9). Remains from iron smithing date mainly to SP III, whereas brasswork may tentatively be ascribed to SP IV or early SP V and is therefore likely contemporaneous with A20 (Cannell et al., Ch. 18:451).

In addition to craft, rotary querns and indications of a voluminous storage capacity for cereals and finds of bread are common traits at Swedish hilltop settlements. This indicates the possibility of cereals being collected at such places, and underlines the importance of everyday commodities in maintaining a hilltop settlement of this type. Nor should we overlook the symbolic value of bread as a Roman-inspired luxury food, or the mythic-poetic motif of bread served to the elite in Rigspula (Ljungkvist 2006:101-2; Olausson 2009:52-5; 2010:9-10). The large volume of cereals found in Area 6 dated to SP IV - A20's assumed period of use - is interesting in this perspective. The designation of this area for the processing and possibly storage of grain suggests that at least one aspect of the strategy behind the A20 construction was to secure the provisions for those dependent on them. The intention and importance of the palisade thus seem rooted in both the actual protection provided and the authority and power expressed in the landscape. 
Brought to you by | UiO - Universitetsbiblioteket Authenticated | m.a.ostmo@khm.uio.no author's copy Download Date | 1/4/18 11:04 AM 